AperTO - Archivio Istituzionale Open Access dell'Università di Torino

\title{
Gut microbiota alteration in Clinically Isolated Syndrome: a pilot study
}

\section{This is a pre print version of the following article:}

Original Citation:

Availability:

This version is available http://hdl.handle.net/2318/1757494

since 2020-10-02T10:17:33Z

Publisher:

SAGE PUBLICATIONS LTD

Terms of use:

Open Access

Anyone can freely access the full text of works made available as "Open Access". Works made available under a Creative Commons license can be used according to the terms and conditions of said license. Use of all other works requires consent of the right holder (author or publisher) if not exempted from copyright protection by the applicable law. 


\section{Abstract: EP1495}

Type: ePoster

Abstract Category: Pathology and pathogenesis of MS - 15 Immunology

Background: Relatively little is known about what might trigger or facilitate the first episode of demyelization in Multiple Sclerosis (MS); recent data indicate that the dysregulation of the immune system that occurs in MS could be controlled by environmental factors. The composition of the gut microbiota structure in terms of species richness and distribution, as well as the functional potential of the community, can greatly impact the host immune system; an imbalance in the gut microbiome has been shown to induce a profound alteration of immune responses both in the gut-associated tissue and in the periphery and could be a risk factor for Aims: As the Clinically Isolated Syndrome (CIS) allows to study the disease processes closest to the biological onset of MS, the aim of this pilot project was to investigate whether alteration in the composition of the gut microbiota could be associated with $\mathrm{CIS}$ and its immune system alteration. Methods: Stool and blood samples were collected from $20 \mathrm{CIS}$ patients and 20 Healthy Volunteers (HV). DNA isolated from stools were subjected to shotgun metagenomic sequencing strategy in order to discover the microbiota composition as well as the microbial function. T helper (Th)17 and T regulatory (Treg) cells were analyzed by FACS in the peripheral blood

Results: Our preliminary results indicate a lower abundance of Bacteroides and a decrease species richness in CIS patients versus HV. In the PB, CIS patients displayed an increase of phatogenic Th17 cells expressing Toll Like Receptor 2 and a decrease of Treg cells producing Interleukin-10 and expressing CD39 compared to HV. Conclusions: These findings indicate that gut microbial dysbiosis could exist at the onset of MS and could be suggestive of a pro-inflammatory milieu observed in the periphery. The analysis on metagenomic content and microbial gene identification will allow us to determined the presence/abundance of specific genes that can be correlated with CIS in order to design strategies to modulate the immune system through alteration of gut microbiome. Disclosure:

Simona Rolla had travel expenses for congress paid by Sanofi-Genzyme; Valentina Bardina: nothing to disclose; llario Ferrocino:nothing to disclose; Stefania De Mercanti had travel expenses for congresses paid by Merck, Biogen, Novartis and Sanofi-Genzyme; Manfredi Ferraro:nothing to disclose; Alessandra Cianflone: nothing to disclose; Roberta Lanzillo received personal compensation for public speaking or consultancies from Biogen, Novartis, Merck, Genzyme, Teva and Almirall; Luca Durelli received personal compensation by Sanofi-Genzyme for partecipating to advisory boards; by Merck for editorial collaborations and had travel expenses for congresses paid by Merck, Biogen, Novartis and Sanofi-Genzyme; Luca Simone Cocolin: nothing to disclose; Marinella Clerico received personal compensation by Merck and Biogen for participating to advisory boards; by Merck for editorial collaborations and had travel expenses for congresses paid by Merck, Biogen, Novartis and Sanofi-Genzyme. 